\title{
Organogenesis in cell cultures of leafy spurge (Euphorbiaceae) accessions from Europe and North America ${ }^{1}$
}

\author{
DAVID G. DAVIS, PRUDENCE A. OLSON, and ROSA L. STOLZENBERG \\ USDA/ARS Metabolism \& Radiation Research Laboratory, State University Station, Fargo, ND 58105, USA
}

\begin{abstract}
:
Plants were regenerated from leafy spurge (Euphorbia esula L.) cell suspensions obtained from stem callus. A North Dakota accession was highly regenerable, but two accessions from Oregon and Austria formed only a few plantlets. Organogenesis occurred in media without growth regulators, under fluorescent lights (30 to $90 \mu \mathrm{E} \mathrm{m}^{-2} \mathrm{~s}^{-1}$, 14-hour photoperiod). Organogenesis was greatest in larger size clumps subcultured during maximum cell growth into media containing a reduced:oxidized nitrogen ratio of 33:67. Roots formed first and some clumps produced shoots. Organogenic suspension cultures also were initiated from hypocotyl and root segments of germinated seedlings, directly in liquid medium. Plantlets of the North Dakota accession formed in vitro adapted to greenhouse conditions. They were phenotypically similar to the parent plants.
\end{abstract}

\section{Introduction}

Leafy spurge (Euphorbia esula L.) is a vigorous, highly competitive perennial weed of Eurasian origin that has spread rapidly over the northern U.S. and Canada and has become an economic pest in the past several years (Watson 1985). Buds form readily on underground parts of the plant and seeds scatter several feet from the parent plant, resulting in extensive areas of pastures, rangelands, recreational areas and roadside ditches becoming dominated by the plant (Lym and Messersmith 1985). Lee and Starratt (1972) were the first to establish callus cultures from roots of leafy spurge seedlings, using NAA, but they made no attempt to regenerate plants from their cultures. In the present

\footnotetext{
${ }^{1}$ Mention of a trademark or proprietary product does not constitute a guarantee or warranty of the product by the U. S. Department of Agriculture and does not imply its approval to the exclusion of other products that may also be suitable.
} 
study, cell suspensions derived from callus were used to establish conditions under which organogenesis occurred in vitro to learn more about the growth and development of leafy spurge in the hopes that that information could be used as part of a rational chemical control program.

\section{Materials and methods}

Cell suspensions were obtained from stem segments of greenhouse-grown plants of a single field-collected accession, designated as 1979ND1 (collected as rootstock in 1979 in southeastern North Dakota) and accessions from the collection of Ebke and McCarty (1983) that were originally obtained from Austria (1978A1) and Oregon (19780R1). Other accessions from several geographic locations were also used to form callus and cell suspensions, but they are not included in this report because they showed little or no inclination to form organs after several attempts. The accessions included in this report were chosen because it was desired to compare a European accession (where leafy spurge may have originated) to North American accessions. The North Dakota accession was phenotypically similar to the Austrian one, whereas the Oregon accession has broader leaves and a more bushy appearance: these three accessions have also been used in chemotaxanomic studies (Manners and Davis 1984, 1987; Mahlberg et al. 1987).

Root material was transplanted into Fargo clay loam soil in plastic pots in a greenhouse with temperatures of $25^{\circ} \mathrm{C}$ and 14 hour daylight. Six-week-old stem segments (grown from root buds) were sterilized 10 minutes with $2.6 \%$ sodium hypochlorite, rinsed twice with sterile water and placed onto agar medium $(0.7 \% \mathrm{w} / \mathrm{v})$ with B5 salts and vitamins (Gamborg et al. 1968) or with MS salts and vitamins (Murashige and Skoog 1962). Either $1 \mathrm{mg} \mathrm{L}^{-1} 2,4-\mathrm{D}$ (alone) or 2,4-D, NAA and kinetin at $0.4,0.4$ and $0.2 \mathrm{mg} \mathrm{L}^{-1}$, respectively, produced good callus (Table 1). Cell suspensions were established from the callus and maintained in liquid B5-1 medium (B5 medium with $1 \mathrm{mg} \mathrm{L}^{-1}$ 2,4-D), and placed onto rotary shakers at 100 cycles $\min ^{-1}$ in darkness. Other suspensions were also obtained later from hypocotyls and roots of aseptically germinated seeds of field-grown plants (from North Dakota). These cell suspensions were obtained directly by agitating hypocotyls and root segments in liquid media.

For regeneration experiments, cells were washed twice with hormone-free medium and inoculated into fresh B5-0 or MS-0 media (containing no growth regulators). Five ml washed cells were added to $25 \mathrm{ml}$ fresh medium in 125 Erlenmeyer flasks, or $0.5 \mathrm{ml}$ of cells of a known weight was placed upon $13 \mathrm{ml}$ agar medium in $6 \mathrm{~cm}$ plaltic petri dishes which were wrapped with Parafilm ${ }^{\circledR}$.

Inocula were obtained from cells 10 to 14 days old because this was the period of maximum growth of cultures which had been grown originally 12 months on B5-1 agar medium (subcultured monthly) followed by 6 months in liquid B5-1 (subcultured every 10 days): dry weights of the cells used for inocula increased from about $22 \mathrm{mg}$ to approximately $145-180 \mathrm{mg}$ per $30 \mathrm{ml}$ media. Inocula $(0.5 \mathrm{ml})$ from these cultures produced the maximum numbers of roots (52 to 127) and shoots (36 to 62) when compared to cells sampled at other times, in a preliminary experiment. Cells were grown under 40 watt cool white fluorescent lights, 14-hr photoperiod. Roots and shoots were counted at 3 weeks 
(flasks) or 6 weeks (petri dishes). Experiments were repeated two or more times, and the data shown are from representative experiments.

Unless otherwise indicated, sucrose was supplied at 2\% (w/v) for B5 medium and 3\% for MS medium. In experiments which compared various ratios of reduced:oxidized nitrogen, 3\% sucrose and a total nitrogen of $27 \mathrm{mM}$ (as in regular B5 medium) were used. Nitrogen salts were supplied as in the original formulations, except $\mathrm{NH}_{4} \mathrm{Cl}$ replaced $\left(\mathrm{NH}_{4}\right)_{2} \mathrm{NO}_{3}$ where appropriate in $\mathrm{MS}$ medium to adjust the reduced form of nitrogen to the indicated value.

Cell suspensions were separated into various clump sizes by passing them through a series of nylon screens with openings $4,2.4,1.2$ or $0.6 \mathrm{~mm}$. The cells were then tested for their capacity to form organs by washing them with hormone-free medium and then inoculating them into B5-0 and MS-0 media. Fewer cells were present in clumps $<0.6 \mathrm{~mm}$ in diameter than in the larger clumps, so the data are reported for these experiments on the basis of inoculum dry weight, rather than per dish. Single cells were not common, and were included with the smaller clump size. Unless otherwise stated, all experiments were performed with cells derived from stem callus of accession 1979ND1.

Plantlets derived from the cell suspensions of accession 1979ND1 were selected and transferred to plastic pots one-half full with a mixture of $50 \%$ peat and $50 \%$ horticultural fine grade vermiculite, watered with $1 / 3$ strength Hoagland's nutrient solution and fitted loosely with a plastic bag over the top to maintain high humidity. The plants were placed under fluorescent lights at room temperature $\left(25^{\circ} \mathrm{C}\right)$ for two to three days and transferred to a greenhouse. The plastic bags were removed within two to three weeks and the plants were adapted to normal greenhouse conditions.

\section{Results}

Callus formed on stem segments of three leafy spurge accessions from Austria, North Dakota and Oregon. Two cell lines of each accession were selected for further subculturing on initiation media, based on their superior growth. After three passages these calli were placed into MS-0 liquid medium for two or three subcultures to test for organogenesis.

Roots were formed in all three of the accessions (Table 1) but the numbers ranged from a few to more than 100 per flask, depending on the accession and on the medium in which the cultures were initiated. The North Dakota accession (1979NDl) produced far more roots in the cell line initiated on B5-1 medium than did the other two accessions on the same medium (Table 1). Cultures from this same accession initiated on B5 medium containing 2,4-D, NAA and kinetin produced more than 100 roots per flask. The results shown in Table 1 illustrate two points: (1) all three accessions shown are inherently capable of organogenesis in vitro but at markedly different capacities, and (2) in vitro organogenesis may be a function of the medium or of callus initiation.

Page 3 of 8 
Calli were initiated from all three accessions on both B5 and MS media with 2,4-D only or with all three growth regulators. However, because many of the cultures grew poorly they were discarded; those shown in Table 1 produced good callus and were maintained for the experiments in this study (and for other studies unrelated to organogenesis).

Shoot formation was more variable than root formation. No shoots were formed from the cell lines of the North Dakota, Oregon or Austrian accessions shown in Table 1 if the cell lines were initiated in B5-1 medium. However, shoots were formed in the cells lines of 1979ND1 and 19780R1 accessions when the cultures were initiated in B5 medium containing all three growth regulators, and in accession 1978A1 initiated in MS medium with 2,4-D alone (Table 1). The North Dakota accession appeared to be much more amenable to organogenesis than the other two accessions, and so was used for further experiments described here.

Table 1. Organogenic capacity of cell suspensions of three leafy spurge accessions. Cultures obtained from stem segments of plants of the same age were grown for three passages as callus followed by three passages in liquid MS-0 media at $85 \mu \mathrm{Em}^{-2} \mathrm{~s}^{-1}$ fluorescent light. $-=$ none observed; $+=>5 ;++=5$ to $100 ;+++=>100$ organs per flask.

\begin{tabular}{|c|c|c|c|c|c|c|}
\hline \multirow[t]{2}{*}{ Media for callus } & \multicolumn{3}{|c|}{$\begin{array}{l}\text { Growth Regulators } \\
\text { in callus media }\end{array}$} & \multirow[t]{2}{*}{ Accession } & \multicolumn{2}{|c|}{$\begin{array}{c}\text { Organs formed per flask in } \\
\text { liquid MS-0 }\end{array}$} \\
\hline & $2,4-\mathrm{D}$ & NAA & KIN & & Roots & Shoots \\
\hline B5 & 10 & 0 & 0 & 1070ND1 & 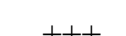 & \\
\hline DJ & 1.0 & 0 & 0 & 1919ND1 & TT+ & - \\
\hline B5 & 1.0 & 0 & 0 & 1978ORI & - & - \\
\hline B5 & 1.0 & 0 & 0 & 1978A1 & + & - \\
\hline B5 & 0.4 & 0.4 & 0.2 & 1979ND1 & ++ & +++ \\
\hline B5 & 0.4 & 0.4 & 0.2 & 1978ORl & + & + \\
\hline MS & 1.0 & 0 & 0 & 1978A1 & ++ & + \\
\hline
\end{tabular}

Table 2. Root formation in liquid culture (Erlenmeyer flasks, $90 \mu \mathrm{Em}^{-2} \mathrm{~s}^{-1}$ ) as a function of clump size and nitrogen status. Values are average numbers of roots per mg dry weight of inoculum (standard errors in parentheses). $\mathrm{N}=9$.

\begin{tabular}{lcccc}
\hline \multirow{2}{*}{$\begin{array}{l}\text { Clump size } \\
(\mathrm{mm})\end{array}$} & Organogenic Medium & $8: 92$ & $33: 67$ & $85: 15$ \\
\cline { 3 - 5 }$<0.6$ & B5-0 & $3(1)$ & $8(2)$ & $1(0.1)$ \\
$0.6-1.2$ & B5-0 & $30(2)$ & $13(1)$ & $13(1)$ \\
$1.2-2.4$ & B5-0 & $17(1)$ & $49(4)$ & $30(1)$ \\
$<0.6$ & MS-0 & $5(0.3)$ & $10(2)$ & $8(1)$ \\
$0.6-1.2$ & MS-0 & $8(1)$ & $22(1)$ & $13(0.3)$ \\
$1.2-2.4$ & MS-0 & $28(3)$ & $58(3)$ & $43(2)$ \\
\hline
\end{tabular}

Page 4 of 8 
The effects of three different reduced:oxidized nitrogen ratios on root formation is shown in Table 2, for clumps of variable size. In all but one case the number of roots formed in a medium with 33:67 nitrogen ratio was greater than those in the 8:92 or 85:15 ratios. In Table 3 is shown a similar situation for inocula of the larger clump size (1.2-2.4 $\mathrm{mm}$ ) but containing variable cell mass. Cells in all clump sizes were rhizogenic although the usual trend was for larger clumps to produce more roots per unit mass than the smaller clumps (Table 2). More variation was observed with the smaller clumps, but the 1.2-2.4 mm clumps outperformed the smaller clumps in both media. There was no consistent relationship between the mass of the inocula and root formation (Table 3 ).

Cell suspensions transferred from B5-1 liquid medium to MS-0 liquid medium formed root initials in 3 weeks (or less). Further transfer to fresh MS-0 or B5-0 liquid media, resulted in shoot formation after an additional 3-6 weeks. In the experiment shown in Table 4, root to shoot ratios from 3:1 to 50:1 were observed, depending on the medium and the sucrose concentration. In this experiment cells grown with $3 \%$ sucrose produced fewer shoots than with $2 \%$ or $1 \%$ sucrose. However, this result was not always consistent in other experiments, so the relationship between sucrose concentration and shoot formation is not well defined in these cultures.

Table 3. Root formation as a function of nitrogen status and inocula size. 1, $1.5 \mathrm{or} 2 \mathrm{ml}$ of cell clumps 1.2-2.4 mm diameter were inoculated into MS-0 liquid medium containing the indicated nitrogen ratios in Erlenmeyer flasks $\left(90 \mu \mathrm{Em}^{-2} \mathrm{~s}^{-1}\right)$. Values are numbers of roots per $\mathrm{mg}$ dry weight of inoculum with standard errors in parentheses ( $27 \mathrm{mM}$ nitrogen).

\begin{tabular}{|c|c|c|c|}
\hline Inoculum dry wt. & \multicolumn{3}{|c|}{ Reduced:oxidized N ratio } \\
\hline \multirow[b]{2}{*}{$(\mathrm{mg})$} & $8: 92$ & $33: 67$ & $85: 15$ \\
\hline & 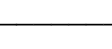 & of roots & \\
\hline $4.2-5.2$ & $36(2)$ & $51(13)$ & $36(13)$ \\
\hline $6.3-7.8$ & $29(3)$ & $56(9)$ & $47(5)$ \\
\hline $8.4-10.4$ & $20(4)$ & $66(5)$ & $45(10)$ \\
\hline
\end{tabular}

Table 4. Effect of sucrose on shoot formation in liquid media (Erlenmeyer flasks, 90 $\left.\mu \mathrm{Em}^{-2} \mathrm{~s}^{-1}\right)$. Roots were initiated in MS-0 medium for 19 days and transferred to fresh MS or B5 media for an additional 6 weeks. Root numbers in the inocula averaged $205+/-30$ and 189 +/- 26 for B5-0 and MS-0 media, respectively. $N=3$.

\begin{tabular}{|c|c|c|c|c|c|c|}
\hline \multirow{2}{*}{$\frac{\text { Sucrose }}{(\%)}$} & \multicolumn{6}{|c|}{ Medium } \\
\hline & \multicolumn{2}{|c|}{ B5-0 } & \multicolumn{2}{|c|}{ MS-0 } & B5-0 & MS-0 \\
\hline & & -- No & ask -- & ------ & \multicolumn{2}{|c|}{ Shoot/Root ratio } \\
\hline & ave & SE & ave & SE & & \\
\hline 1 & 30 & 11 & 67 & 34 & 3 & 7 \\
\hline 2 & 40 & 25 & 18 & 14 & 10 & 5 \\
\hline 3 & 18 & 10 & 3 & 3 & 50 & 10 \\
\hline
\end{tabular}


Cell suspensions capable of organogenesis also were formed directly from hypocotyls and root segments of aseptically germinated seedlings that were placed directly into liquid without going through a callus phase (Table 5). All of these cultures formed roots when they were transferred (after four passages) from B5-1 liquid medium to MS-0 liquid medium (Table 5).

Table 5. Root initiation from suspensions derived directly from hypocotyl or root segments placed into liquid B5 or MS with the indicated growth regulators for three subcultures. Tests for regeneration were done in MS-O liquid medium $\left(90 \mu \mathrm{E} \mathrm{m} \mathrm{m}^{-2} \mathrm{~s}^{-1}\right)$ at the fourth subculture with $25 \pm 5 \mathrm{mg}$ dry weight inocula. $+=<20$; $++=200$ to 500 ; $+++=>1000$ roots per flask.

\begin{tabular}{lccccc}
\hline $\begin{array}{l}\text { Original } \\
\text { Explant }\end{array}$ & \multicolumn{3}{c}{$\begin{array}{l}\text { Growth regulators } \\
\text { in initial medium }\end{array}$} & & \multicolumn{2}{c}{ Transferred to MS-0 from: } \\
\cline { 1 - 4 } & $2,4-\mathrm{D}$ & NAA & Kin & B5 & MS \\
\cline { 2 - 4 } Hypocotyl & 1.0 & 0 & & ++ & + \\
& 0.4 & 0.4 & 0 & & +2 \\
Root & 1.0 & 0 & 0 & + & +++ \\
& 0.4 & 0.4 & 0.2 & + & ++ \\
\hline
\end{tabular}

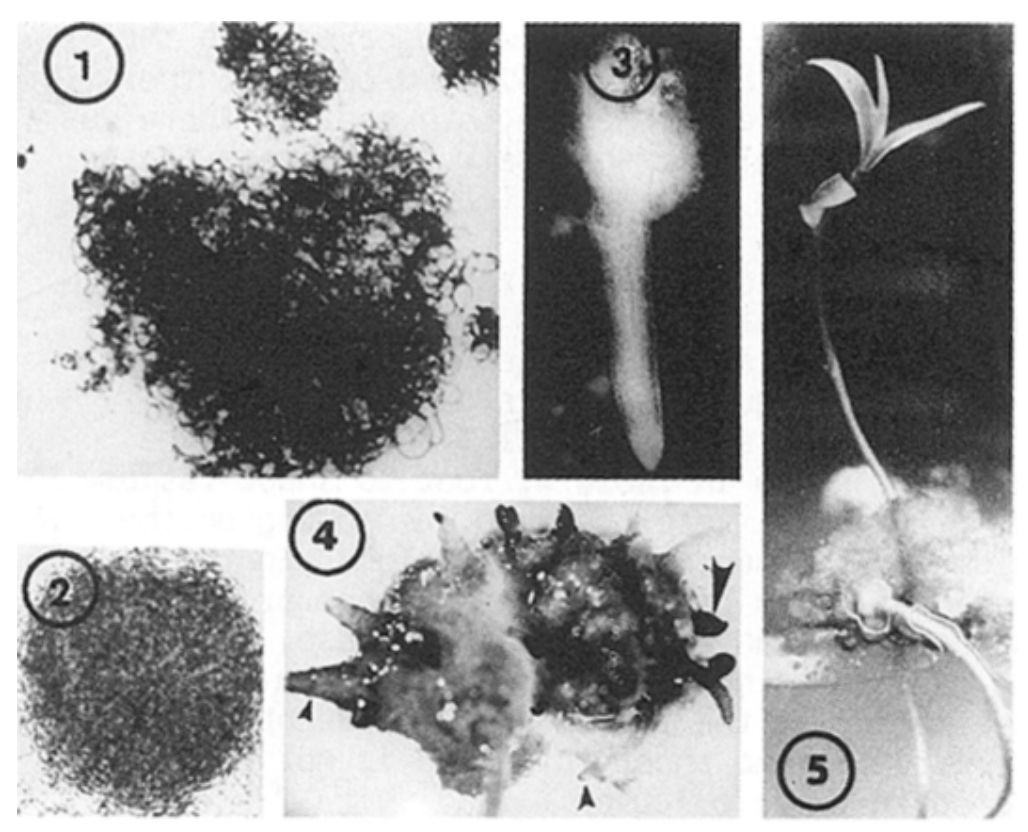

Figures 1-5. A typical sequence of events during regeneration of leafy spurge plants (accession 1979ND1) from cell suspension culture.

Fig. 1. Cell clumps grown with $1 \mathrm{mg} \mathrm{L}^{-1}$ 2,4-D (50 X).

Fig. 2. Spherical clumps form after transfer to a medium without 2,4-D (73 X).

Fig. 3. A root on a cell clump (1.2 X).

Fig. 4. Numerous roots (small arrowheads) and shoots (large arrowhead). The dark pigments are presumed to be anthocyanins $(7 \mathrm{X})$.

Fig. 5. A plantlet prior to adaption to the greenhouse. The leaves are typical of the accession $(0.9 \mathrm{X})$. 
Figures 1-5 illustrate the usual sequence of events that occurred when suspension cultures were subcultured to media without 2,4-D and the subsequent development of plantlets which could be adapted to the greenhouse.

The regenerated plants were phenotypically similar to the greenhouse-grown 1979ND1 accession (Fig. 5). They differed from the original accession in that they grew more slowly and did not flower in the greenhouse.

\section{Discussion}

During the early phases of this study, it was believed that the only leafy spurge accession with the capacity to regenerate from cell suspensions was the North Dakota accession, since early attempts to regenerate the Austrian and Oregon accessions and other cultures from Idaho, Nebraska and Minnesota (accessions 1978ID2, 1979NE1, 1979MN1, respectively) were not successful. It appeared that leafy spurge lost the genetic capacity for regeneration when placed into culture (with the obvious exception of 1979ND1). However, this proved untrue, as the Austrian and Oregon accessions did form organs, with some difficulty and in low numbers. Organogenic cell suspensions were also formed readily from hypocotyls grown from seeds of diverse parentage, without going through the callus phase. There was no evidence of somatic embryos being formed, as occurs with carrot cultures derived directly from hypocotyls (Nomura and Komamine 1985).

Root formation appears to be the end point for callus cultures of many plants, so that if roots form first, shoots usually do not (Burgess 1985). However, in leafy spurge, the usual pattern of development in cell suspension cultures was to form shoots on cultures that rooted first. Only very occasionally were shoots formed prior to roots in this study. In some experiments, shoots were not observed at all; perhaps the experiments were terminated too soon.

The effects of exogenous growth regulators are not described in this study because the results of numerous experiments were extremely variable and often contradictory. The fact that entire plantlets could be formed without exogenous growth regulators indicates that the cultures were capable of producing their own at the proper ratios, if grown sufficiently long in hormone-free media and if carryover of 2,4-D, NAA or kinetin with the inocula was minimized by washing of the inocula with hormone-free medium. The endogenous levels of growth regulators need to be determined in these cultures to assess their relationship to organogenesis.

The nitrogen status of the medium was investigated because the results of early experiments indicated that cells transferred to B5-0 medium often produced more roots than those in MS-0 medium, but the roots did not develop as well as in MS-0 medium. The differences were initially thought to be due to the higher sucrose concentration being used in MS medium than in B5, but this was not borne out by experimentation. Organogenesis in leafy spurge does not appear to be coupled closely to the nitrogen status of the culture: at least not to the extent reported for somatic embryogenesis in several other cell culture systems (Hyndman et al. 1982, Kamada and Harada 1979, Masuda et al. 1981, Thomas and Street 1972, Wetherell and Dougall 1976). Leafy spurge cells were capable 
of organogenesis in a wide range of reduced:oxidized nitrogen combinations, but the ratio used in MS medium (33:67) appears to be somewhat more favorable than others.

The persistence of leafy spurge as a perennial noxious weed in nature is not surprising, considering the diverse conditions under which cells formed organs in this study. The problem comes in sorting out which factors are most significant in the development of the plant and whether those factors are unique enough to be able to apply rational control methods by chemical inhibition of key growth processes.

\section{References}

Burgess, J. (1985) An Introduction to Plant Cell Development, Cambridge Univ. Press. p 146.

Ebke, D. and McCarty, M. (1983) Weed Science 31: 866-873.

Gamborg, O.L., Miller, R.A., and Ojima, K (1968) Exp. Cell Res. 50:148-151.

Hyndman, S.E., Hasegawa, P.M., and Bressan, R.A. (1982) Plant Cell Tissue Organ Cult. 1:229-238.

Kamada, H. and Harada, H. (1979) Z. Pflanzenphysiol. 91:453-463.

Lee, T.T. and Starratt, A.N. (1972) Can. J. Bot. 50:723-726.

Lym, R.G. and Messersmith, C. (1985) J. Range Management 38:149-154.

Mahlberg, P.G., Davis, D.G., Galitz, D.S., and Manners, G.D. (1987) Bot. J. Linnean Soc. (London) 94:165-180.

Manners, G.D. and Davis, D.G. (1984) Phytochemistry 23: 1059-1062.

Manners, G.D. and Davis, D.G. (1987) Phytochemistry 26: 727-730.

Masuda, K., Kikuta, Y., and Okazawa, Y. (1981) Japan J. Crop Sci. 50:125-130.

Murashige, M. and Skoog, F. (1962) Physiol. Plant. 15:473-497.

Nomura, K. and Komamine, A. (1985) Plant Physiol. 79:988-991.

Thomas, E. and Street, H.E. (1972) Ann. Bot. 36:239-247.

Watson, A.K. (1985) Leafy Spurge Monograph No. 3, Weed Sci. Soc. Amer. Champaign, IL.

Wetherell, D.F. and Dougall, D.K (1976) Physiol. Plant. 37:97-103.

Page 8 of 8 